\title{
Complications Connected to Using the Impact Factor of Journals for the Assessment of Researchers in Higher Education
}

\author{
Valentine Joseph Owan ${ }^{1 *}$ (D), Mercy Valentine Owan ${ }^{1}$ (D)
}

${ }^{1}$ Department of Educational Management, University of Calabar, Calabar, NIGERIA

*Corresponding Author: owanvalentine@gmail.com

Citation: Owan, V. J., \& Owan, M. V. (2021). Complications Connected to Using the Impact Factor of Journals for the Assessment of Researchers in Higher Education. Mediterranean Journal of Social \& Behavioral Research, 5(1), 13-21. https://doi.org/10.30935/mjosbr/10805

\begin{abstract}
The use of impact factor (IF) in the scientific and academic world is not new. A phenomenon that has gained widespread recognition and utilization. However, in modern-day usage, there seems to be a trend in higher education where academics are evaluated based on the impact factor of journals where scholarly works are published. This trend is gradually shifting the paradigm from the assessment of research contents to publication venue. This does not align with the original purpose of IF conceived by Garfield in 1955. One question that has continued to agitate the minds of concerned academics is whether the IF of journals is a dependable measure of research quality. This paper is an attempt to clarify or address this problem. Based on a thorough literature search and filtration, several problems about the use of IF as research quality measure are discussed as well as their implications. Recommendations were also made aimed at providing a way forward in higher education.

Keywords: evaluation, higher education, impact factor, journal, measure, research

Received: 7 Jan. $2021 \bullet$ Accepted: 3 Mar. 2021
\end{abstract}

\section{INTRODUCTION}

Research remains one of the central sources of knowledge creation, problem-solving and the modification of obsolete information world over. Research is crucial to fostering socio-economic growth and productivity, resulting in a variety of periodic assessments being carried out in various economies to track their processes, stimulate quality change and evaluate policy blueprints intended to improve them. Considering its importance, there is a need for research output in higher education to be assessed and evaluated for scientific quality. Research quality assessment is necessary to inform research policies at national and regional level; to inform institutional strategic planning; to distribute funding selectively; to promote quality development at individual and organizational levels; to minimize information asymmetry between knowledge suppliers (research institutions) and demand (students, companies); and, last but not least, to demonstrate this to investors (Abramo \& D’Angelo, 2016).

The number of research publication is increasing exponentially (Larsen \& von Ins, 2010), making it increasingly very difficult for scholars to follow the publication trends in the literature (Aragon, 2013). Consequently, it has become even more difficult for young researchers and scholars to identify works that have made substantial and significant contributions to a particular field and to discriminate between low- and high-quality papers. Such knowledge of what constitutes a significant contribution made by research which aids in discriminating between standard and low-quality research is usually gained by researchers through several years of experience (Aragon, 2013). This problem is created partly by the scientific structure favouring the productivity of research(ers), as identified long ago (Margolis, 1967). It has been a contentious discussion among different scholars on how the quality or productivity of research(ers) should be measured or determined.

In time past, this need has been met through peer review (a system where qualified experts in a particular field scrutinise pre-published and/or published researches to ascertain their scientific quality). Ideally, peer evaluation using appropriate guidelines is a good way to determine the value or quality of scientific output from a research process. However, peer review and expert assessment are not without problems as it is imperfect and/or subjective (Ioannidis et al., 2010). It is an assessment usually based on other individuals' judgment, giving room to bias (Solimini \& Solimini, 2011). For instance, it has been reported that some journals assign articles submitted for publication to reviewers with general competence in the subject rather than specific knowledge of the particular field of the article (Joshi, 2015). The qualitative and subjective nature of peer review as a research evaluation method has brought its reliability into questions (Haddawy et al., 2016). Issues such as reviewers bias, conflict of interest, the tendency of reviewers to evaluate according to their writing style, interest and language, geographical, demographic and institutional preference (e.g. favouring 
or disfavouring researches from certain countries, regions, institutions, rank, age group of researchers based on their perceived reputation) (Butler \& McAllister, 2009; Langfeldt, 2001; Martin \& Irvine, 1983; Smith, 1988). Due to these problems, there was a need to provide a solution by developing a more reliable system that could be used to evaluate the scientific quality of research in higher education and beyond.

The impact factor (IF) was developed by Eugene Garfield in 1955 to enable scientist and scholars search for the bibliographic references for their scholarly or scientific contributions, (Garfield, 1955; Kieling \& Gonçalves, 2007). This was only going to be made possible through citations count - a situation where an author receives credit each time their work is used (cited) by other researchers. The impact factor was proposed originally to remove citation counts bias so that large or small, frequently issued or less frequently issued, old or new journals can be appropriately evaluated. This is because large, frequently issued and old journals attract more citations than small, less frequently issued or new journals respectively. However, it was later submitted in 1972 that citations could be used to ascertain the importance of a journal (Garfield, 1972). This indicates that journals that are widely cited are widely utilized and should be accorded reputable statuses, although there are rarely cited journals that are widely utilized (Buela-Casal \& Zych, 2012). It was further maintained that librarians could find impact factor as a useful tool in managing journal subscription and collections; while authors could find it useful when searching for their scholarly works and editors could use it to determine some important parameters of their journals (Buela-Casal \& Zych, 2012). Thus, it makes sense to state that the IF was developed as a response to the failed peer-review approach to research evaluation. The IF was created as a means of using articles' average number of citations over a given duration to determine the quality of a journal.

One of the most widely discussed subject in higher education internationally and Nigeria specifically is the impact factor. This may be attributed to the mainstream use as a quality assessment measure of the impact factor. In addition, because of the importance of research performance appraisal, which is becoming a very important topic at the entity, research community, department and institutional levels (Mingers \& Yang, 2017). Several discussions and arguments abound regarding the use of impact factors for research evaluations (Chapman et al., 2019; Hammarfelt \& Rushforth, 2017; Koya \& Chowdhury, 2017; Leydesdorff et al., 2016; Mårtensson et al., 2016; Rushforth \& de Rijcke, 2015; Saha et al., 2003; Seglen, 1997a, 1998). Related questions were also raised about the relevance, durability and persistent use of IF as a metric of research quality (Aksnes et al., 2019; Blyth et al., 2010; BuelaCasal \& Zych, 2012; Cheek et al., 2006; Elliott, 2014; Fallon et al., 2015; Jarwal et al., 2009; Lippi \& Mattiuzzi, 2017; Mårtensson et al., 2016; Saha et al., 2003). It has also been discovered that despite the development of impact factors, as a means of eliminating bias, review articles attract more citations than original research papers (Kieling \& Gonçalves, 2007). This paper seeks to use a literature review to answer a similar research question - is the use of Impact Factor a Dependable Measure for Evaluating Research(ers) in Higher Education?

\section{MEANING OF IMPACT FACTOR AND ITS COMPUTATION}

A journal's impact factor corresponds to the total amount of citations attracted by a journal for its published articles, divided by the total number of citable articles published by the journal over a span of time. It is simply the quotient obtained after finding the average of total citations recorded by a journal within a period and dividing the results by the total number of published works that are citable within the same period. It is an annually calculated metric for each scientific journal reflecting the mean number of times articles in such journals have been referenced in articles published by other journals (Alberts, 2013; Kieling \& Gonçalves, 2007). The computation of journals IFs is done annually in Philadelphia by the Institute for Scientific Information (ISI) Web of Science (WoS) owned by the Thompson Scientific and published in the Science Citation Index (SCI), Social Science Citation Index (SSCI) and the Journal Citation Reports (Baum, 2011; Kieling \& Gonçalves, 2007; Kochen \& Himmel, 1998). It must be noted that the IF of a journal applies only to journals and not authors, individuals, institutions, subgroups of published papers nor research groups (Abambres et al., 2016).

Some citable items are used in the denominator when calculating the IF of a journal. Such citable items include research articles, proceedings and review papers that contribute to the existing body of knowledge in a field and that are most likely to be cited by other scholars. Citable items exclude other forms of journal contents such as editorial releases, abstracts, letters to editors. The ISI is yet to fully conceptualise what should practically constitute a citable item, consequently, it is yet to be known whether such materials as books, chapters in books, and academic theses or dissertations are citable or non-citable items. The IF is calculated by first, taking statistics of a journal's total published output; determining how many times some or all of these articles have been cited (referenced) by the same or other authors in other articles; the total number of citations is then divided by the total number of publications.

In general, the IF of a journal for the current year is estimated over two years by determining the quantity of citations received from separate papers published in a journal for the previous two years and dividing the estimate by the total number of papers published in the same period by the journal. For instance, by adding the total number of citations that articles published in 2018 and 2019 has received by a journal and dividing the value by the total number of articles the journal has published in 2018 and 2019, the two year IF can be calculated in 2020. This is expressed mathematically in the formula below:

$I F_{2020}=\frac{\text { Number of citations in } 2018+\text { Number of citations in } 2019}{\text { Total number of publication in } 2018+\text { Total number of publication in } 2019}$

The numerator is the aggregate amount of citations articles published in a journal has received in the preceding two years; while the denominator is the sum of the total number of articles published in a journal in the preceding two years. It is explained that "the numerator includes articles, editorials, and letters to the editor, while the denominator consists only of articles" (Fu, et al., 2011, p.588). ISI has recently adopted a five-year impact factor where the total amount of citations for a journal for its published articles in the preceding five years is divided by the amount of the total number of publications in the preceding five years by the same journal. This was done to account for variations in the rate of article obsolence through fields (Baum, 2011). 


\section{USING IMPACT FACTORS TO EVALUATE RESEARCH QUALITY: THE PROBLEM}

The impact factor of journals tends to be in wide use as a standard for judging the quality of research and researchers. Universities world over, are using journal rankings and IF to measure the individual research impact of academics across various disciplines (Gruber, 2015). Most higher education institutions in Nigeria prefer to use the mere publishing of papers in impact factor journals as a criterion for measuring the scientific output of all academic staff. In the context of Nigeria, this has stirred up so many problems discussed below.

\section{It can be Easily Manipulated}

Many scholars now manipulate their scores through practices such as either one or all of self-citation, forcing other researchers to cite their work during peer reviews, or liaising with colleagues to cite them while promising to cite their colleagues work in return (creating an n-way symbiotic barter system of "cite-me I cite you"). Other IF inflationary or manipulative techniques include the publication of more review articles and few letters to the editor and case reports which are not frequently cited (Sevinc, 2004), rejecting papers perceived as having lower citation chances (such as papers written on a very specific topic) notwithstanding its sound quality (Agarwal et al., 2016), editors trying to boost their journal IFs by unethically requesting that authors cite unrelated papers published by their journal (Baum, 2011) or through attempts made to annually publish editorial referencing which is a questionable act (Huggett, 2013; Mahian \& Wongwises, 2015). All these dubious acts are unacceptable and may damage the reputation of authors, journals, and editors fraudulently trying to manipulate the IF.

\section{Unreasonable Hindrance to Academic Growth}

Many academic staff in some Nigerian universities have been denied promotions at different levels for not publishing a certain ratio of their researches in journals with impact factor. Many institutions (including those in Nigeria) do not know how to use the impact factor as a metric while others do not also seem to be acquainted with it (Agarwal et al., 2016); they use it inappropriately. Furthermore, the high rate of reliance on the journal IF as a research evaluation tool hinders the growth of several academics who are unable to publish a certain quota of their articles in journals with impact factors. In other words, sound researches published in a low or non-impact factor journal are discredited as having little effect on the discipline, while the victim bears the loss of such outcomes.

\section{It Increases Unethical Practices in Academia}

The use of impact factor by ISI tends to have created many unethical practices among journal editors and authors. Issues of self-citation and the intentional forcing of authors to cite a journal's previously published articles as a means of qualifying an article for publication in a journal are common practices that are not unconnected to citations and impact factor (metrics). The high emphasis on the use of IF for research evaluation appears to have created another problem of deceit where some non-indexed journals in Thomson Scientific Web of Science are now generating IFs that are very high and questionable. Different bodies have also emerged in recent times which assign IFs to journals that are considered predatory and non-reputable. This misleads many scholars into publishing in them just to meet promotion obligations or conditions. For example, the International Scientific Indexing (ISI) (https://bit.ly/3cyG94Z); the Scientific Journal Impact Factor (SJIF)
(https://bit.ly/2WXPtZJ); the Journal Impact Factor (JIF) (https://bit.ly/2X2dgrk) offers impact factors to many non-indexed journals in Web of Science (WoS) respectively. Most of these journals are considered predatory in Jeffry Bealle's list as well. Predatory journals are journals that publish anything sent to them without any rigorous peer review or assessment so long as money is paid. This constitutes a "thorn" to academia; they have caused a lot of troubles (Bohannon, 2013; Chapman et al., 2019).

\section{It cannot Measure the Quality of Research Adequately}

The original idea of Garfield (the creator of impact factor) was to enable librarians sort journals based on citations to ascertain which to index in a library collection (Alberts, 2013; Baum, 2011). However, the problem started in the last two decades when in 1992, Thomson Scientific transformed the usage of IF after acquiring ISI, from a device used to sort journals to a tool showcasing the quantitative value of journals, articles and authors. It is now widely known that the impact factor is now a device used in assessing researchers, judging the scientific quality of a journal, and published articles (Alberts, 2013; Baum, 2011; Eston, 2005; Quan, et al., 2017); as well as, a device used in peer review and the determination of which researcher to hire and offer grants.

The abuse by most institutions in the use of impact factor in evaluating research quality, recruiting and appraising staff and/or making tenure decisions is hurting to the academia and contributes greatly to the long list of criticisms labelled against the use of impact factor. This poor use of impact factors has led to even Garfield questioning the misleading and inappropriate use, especially in the context of promotion and tenure decisions (Garfield, 1999, 2006). It is for this reason that a researcher observed that different scientists now annotate each of their research publication alongside the impact factor of the journal which published such researches to three decimal places. It has been discovered that in some nations, research work is considered to have a zero value if it is published in a journal with IF below 5.0, which is a very wrong practice condemned by many leading scientists (Alberts, 2013; Chapman et al., 2019; Sugimoto et al., 2017).

Furthermore, it is well documented that data fabrication, falsification, grammatical errors and plagiarism are used in assessing the scientific quality of a research report (Bassey \& Owan, 2019; Odigwe et al, 2020; Owan \& Bassey, 2019). However, using the IF as a quality measure does not account for these aspects of research quality. Thus, a high impact factor attached to a journal without a strong peer review base may be misleading, as a thorough scrutinization of published works through post-publication review may reveal weaknesses. Good reasoning, analytical structure and methodology, relevant statistics (if applicable), strong logic and proper citation of literature must be used in quality assessment. Other critical aspects of research quality are Immediate utility, relevance for scientific research, reputation and rigour of technique (Saha et al., 2003).

This raised a pertinent question: are articles published in journals with high impact factor more quality than those published in low impact factor journals? the answer is obviously "no"; it is not a dependable measure of research quality. In some Nigerian universities, for instance, it is also mandatory that academics list out all the published works alongside the impact factor of the journals which published such articles by the side in their resume. Thus, journals with high IFs are considered more reputable than others with low or no IF. This constitutes another setback because Some articles are never quoted by 
other scholars, even in journals with the largest impact factors, whereas others are cited improperly. The IF has been discredited as a reliable tool to measure research quality and probably a qualitative measure (Hallberg, 2012). The reliance on the citation rate as an impact measure perversely discourages research in overlooked fields that merit greater analysis (Casadevall \& Fang, 2014).

\section{It may Enable Low Standards in Research and Practice}

The problem of poor research quality resulting from the "publish or perish" paradigm has further been boosted through the introduction of quantitative metrics (such as impact factors, h-index and many others) which all tend to favour the ideology of productivity (Agarwal et al., 2016; Aragon, 2013). As noted by a scholar, for the most part, the "publish or perish" paradigm that bedevils researchers has inescapable impacts on the quality of published research (Aragon, 2013). Due to this drive, it is not uncommon these days to find many researchers splitting the findings of their researches into smaller units (instead of producing a single meaningful manuscript) just to increase the number of publications, as well as the chances of gaining citations from multiple sources to improve journal and author level metrics. This decreases the quality of findings reported in many published articles. A scholar disclosed that there is a possibility that poor- or modest-quality papers will be cited more often than, as would be predicted, high-quality papers (Hallberg, 2012). It is also documented that all the procedural operations that give birth to the research product are related to the consistency of the research production; as well as, the quality of the researchers and the reporting quality of the scientific publication (Solimini \& Solimini, 2011).

\section{The IF can be Impacted by the Skewness of Citations}

The impact factor, like other metrics, has tendencies to be promoted due to citation skewness (Baum, 2011; Folly et al., 1981; Seglen, 1992; Wall, 2009). Citation skewness is influenced by factors such as academic rank, geographical location, experience and institutions of authors, prestige and reputation of journals, author institution and journal publishers, as well as the language used in writing the research report. Other factors that skew the impact factor of journals include the subject area of the journal, journal size, publication type (research articles, reviews, etc), number of contributors, terms used in abstract, pace of publishing and limitation of citable elements in the denominator of the IF formula (Joshi, 2015). The nationality of an author influences the number of citations of articles (Kieling \& Gonçalves, 2007).

For instance, a study disclosed that there is bias in IFs in favour of the U.S and that there are heavy distortions of IF based on speciality making it quite vulnerable to technical problems (Kochen \& Himmel, 1998). Many authors from developing nations (such as African nations) have a high rate of rejection in top-quality journals more than their counterparts in western and European nations (Kieling \& Gonçalves, 2007), which puts them in a disadvantage position to publish in high citation-attracting journals. Hypothetically, it is very easy for say - a professor at MIT or Cambridge university to have a low-quality article published in a top journal than a professor in any university in Nigeria with high-quality research. Furthermore, it is very difficult to evaluate journals across different disciplines using the IF metric (Kressel, 2014).
Not All the Details About the Impact of a Journal are Provided by the IF

Simply put, the journal IF does not give a full picture of the impact of a journal, since it mainly describes the research activity arising from a publication. Furthermore, the high impact factor of a journal may be dependent on quotations from only some of the papers written, which leave the others with a few to no citations. The impact factor, like other metrics, has been discredited for its lack of information by other scholars (Campbell, 2008; Cheek et al., 2006; Gruber, 2015; Hallberg, 2012; Kressel, 2014; Rowlands \& Nicholas, 2007; Seglen, 1992). Thus, other approaches are necessary to cover up for the overlapping weaknesses of IF. The use of internet downloads, readings and use rates is now being studied in current practice as a way of further understanding the effect of a science publication on its readers or community.

The impact factor is also misleading because articles with little impact may be published in highly rated journals or journals with a high impact factor, whereas articles with a high impact and possible impact may be published in lower ranked journals or journals with a low impact factor. The problem of IF obsession has been suggested to be connected to the increasing business orientation in higher education and among many publishers (Gruber, et al., 2010; Parker \& Jary 1995; Willmott, 2011) and the neo-liberal nature of the higher education system (Burrows, 2012; Craig, et al., 2007; Sauder \& Espeland 2009; Shore 2010). The marketing in higher education is not therefore a positive idea and represents what scholars have tagged as an "academic sell-out" (Gruber, 2015) or "malady" (Seglen, 1997b). This can be likened to the same way musicians switch record labels, change musical pattern and values for money-making, popularity and other commercial reasons. It is very rational that academics chase after such incentives, but not in the best interest of humanity, society and academia (Schekman cited in Gruber, 2015).

\section{Prejudice in the Formula of the Impact Factor}

There is bias in the impact factor formula as the scope of the socalled "citable items" in the denominator is narrow. Only research articles, reviews and notes are considered as citable items in the denominator, while a broad range of article types are allowed in the numerator of the formula. The numerator contains an aggregate of citations recorded articles such as all those in the denominator, as well as letters, meeting abstracts and editorials (Hernan, 2008). The numerator-denominator inequality and the introduction of the term "citable items" in the denominator of the IF formula creates a bias. This bias increases to a considerable extent, the IF of journals. The IF formula has no normalization (at the time of writing) to smooth-off the effect of self-citation contribution to the IF. Consequently, it has been reported that many editors can gamble through either one or all of influencing authors to cite previously published works of their journals, reducing the acceptance or publication rate of articles and favouring the publication of review articles which are known for attracting more citations (Smith, 1997; Neuberger \& Counsell, 2002; Whitehouse, 2001). However, it has been revealed that separate self-cite indicators are now reported in the Thompson Reuters database to account for the contribution of self-citation to a journal IF (Rousseau, 2002).

Considering that novel findings often take over two years for their impact to be noticed or fully realized (Lawrence, 2007), another critique labelled against the formula is that resulting from the assumption that two years period is sufficient to measure the impact of research. Such 
assumption led to the inclusion of a two-year window as the period allowed in the IF formula. Due to this reason, the two year allowed as citation window in the IF formula has also been queried for not being broad enough to accommodate all recently published works in a field (Solimini \& Solimini, 2011). Another major flaw in the formula is that some journals may find most novel and creative research less appealing because, by its very existence, such analysis would have a significant effect at a time when it does not add to the computation of the IF.

\section{It Results in a Shift in Research Direction}

The over-dependence on the IF of a journal changes the research focus of many researchers who may decide to leave certain crucial and groundbreaking research areas to other areas, they feel will attract more citations to their articles. Also, many academics may also seldom conduct primary investigations and laboratory experiments and promote the writing of reviews just to boost the chances of their paper being accepted by a high IF journal. This switch in focus, from a paper quality and contents to publication venue caused by IF mania is one of the greatest distortions (Casadevall \& Fang, 2014) which can damage the higher education system. Moreover, the switch encourages scientific branding in favour of journals' commercial activities. Hence, the publication venue now decides, to an extent, the likelihood or probability of receiving research grants, academic promotion, awards, appraisal and so on. The warped set of principles has become independent of journal editors with a great deal of intensity and power than is good for research practice.

\section{It Delays Scien tific Knowledge Development}

One characteristic of most high impact factor journals is a delay in the peer review and editorial decisions on a submitted article. As earlier explained, many authors, in an attempt to publish in these top IF journals submit articles to them creating a pool of several articles for one journal. Again, considering that many high IF journals are manipulating their approach to gain higher IF scores, they publish few articles (that should supposedly attract quick citation) based on laid down rules. This creates a very high rejection rate for articles submitted to them. Consequently, meritorious articles of sound scientific or academic reputation that would have made a substantial contribution to society are rejected (after several months of waiting for review results). These authors have no other option but to locate another journal with a high impact to submit the same article for peer assessment (which would require another wait time). This method slows down the generation of scientific information which should be disseminated rapidly.

In an attempt to beat this delay, many authors submit one work to multiple journals simultaneously (Casadevall \& Fang, 2014), which is an unethical research practice (Bassey \& Owan, 2019). Multiple submission is reported to consume the time of reviewers and editors. In some cases, editors would request that further experiments be conducted (in an aspect they think could attract more citations) to a well-researched and reported study to convince them to accept submitted articles. Such an additional task consumes a lot of time, energy and resources. The delay in the publication of research works may affect the society directly or indirectly especially when such research contains a vital solution to a problem, that could lead to the production of new vaccines or improves previously known methods, knowledge or systems. Imagine the delay of an article with a framework for developing vaccines to treat Covid-19 patients just because of academic gambling. Simply put, the duration expended in an attempt to identify a high IF journal can also decrease the chances of early citations and discourages scientific and academic innovation. As explained by a scholar, much emphasis on metrics incentivise researchers to work in densely crowded areas of research, since it is only in these fields that it is possible to expect vast numbers of scientists to apply somebody's work, no matter how excellent.

\section{It is Only Computed for Journals Indexed in the Thomson Reuters Database}

In the context of Nigeria, like many other African societies, many journals are domiciled in higher academic institutions (HAIs). In the social or behavioural sciences (including education) most of the journals are not indexed in the Thomson Reuters Web of Science (WoS). Using the IF as a quality device would suggest that all journals non-indexed in the ISI database are not important since they do not have impact factors. This is because "no IF is available if the journal is not indexed by Thomson Reuters" (Solimini \& Solimini, 2011, p.98). By implication, non-Thomson Reuters indexed journals should not produce research in higher education if the IF is used to undermine the place of peer review and expert judgment. Such an indicator (IF), like other metrics, when used inappropriately is misleading (Biagioli, 2018; Grech, 2018; Hammarfelt \& Rushforth, 2017; Lippi \& Mattiuzzi, 2017; McKiernan et al., 2019) and adds to the long list of reasons why the IF in particular (Chapman et al., 2019; Gruber, 2015; Kiesslich et al., 2016; OrduñaMalea et al., 2016; Weale et al., 2004) and other metrics, in general, are not perfect measures of research quality. As earlier discussed in problem 3, many bodies other than the ISI are now providing IFs to thousands of journals non-indexed in the Thomson Reuters database, just to follow the impact factor trend to be relevant.

\section{Death of Many Institutional Journals}

Due to the non-indexation in the WoS, many Nigerian journals which have served in most higher education institutions for decades have either died or are on the verge of dying. This is due to the switch from "traditional journals" (without impact factors) to IF journals as the "best" or "reputable" venue for scholarly publications. The switch in most universities research evaluation guidelines, with emphasis on IF, has turned the attention of many scholars towards IF journals. Consequently, many institutional journals seldom receive manuscripts for peer review and possible publication. The lack of patronage has/is gradually killed/killing the efficacy and/or sustainability of many respected institutional journals.

\section{Rejection of Meritorious Articles}

Due to the need to trim down the number of publications to improve the IF, many journals reject a lot of quality researches that are perceived by some editors as not having the potential to attract immediate citations. In a Nature editorial, it was documented that journals reject many quality articles due to their low perception and sight of the immediate impact of the paper (Nature, 2003). By so doing, journals could be turning down great findings that can reshape the world. Just like a wicked woman could be aborting a child that may become the president of a nation. 


\section{CONCLUSION AND RECOMMENDATION}

The review of the literature shows that the Journal Impact Factor (JIF) is not a dependable measure of research quality. This is because of the numerous limitations levelled against it which are far beyond its supposed strengths. Following the original specification by Gartfield (1955), the IF was not intended to measure research quality, indicating that the impact factor has been misused. Research quality is quite a complex topic to measure quantitatively, hence, a single metric cannot provide an objective and unbiased measurement. The use of different metrics with overlapping strengths and weaknesses could serve a more useful purpose than merely relying on the Journal IF. It is also advocated that the quality of research be evaluated through a rigorous pre- and post-publication peer assessment to supplement metrics (such as the number of publications, IF, h-index, and so on). Based on the limitations, higher institutions of learning should desist also from the use of IF in appraisal, promotion or tenure decisions but focus on the unique contributions of the research (Casadevall \& Fang, 2014). Based on the conclusion reached, other recommendations made to address some of the problems associated with the use of IF as a quality assessment device are.

i. Research evaluators, academic administrators or assessment panels should be enlightened that the IF of a journal or publication venue is not a sufficient factor in determining research success or quality. Therefore, they should adhere strictly to the DORA principles (Misteli, 2013) which can be retrieved from https://bit.ly/2y4Q0Rh

ii. When using peer review to supplement metrics, researches should be allocated to reviewers with specific expertise in the area. Also, reviewers asked to evaluate other researchers' work from another field, should ensure to do a thorough reading to acquire a level of familiarity with that field. Hence, there should be a provision for interactive opportunities among researchers across disciplines through seminars, workshops, symposiums, and conferences to stimulate inter- or multi-disciplinary research.

iii. Top journals should therefore raise the number of publications published per issue in order to prevent unnecessary dismissal of articles of meritorious nature. This would eliminate the problem "we regret that we receive many more meritorious submissions than we can publish" (Casadevall \& Fang, 2014, p.4). Expanding the number of articles per issue would eliminate this problem, giving room for the publication of many quality articles, speeding the production of scientific knowledge.

iv. Annual and semi-annual journals with high rejection rate should also consider increasing their publication frequency to quarterly, bi-monthly or monthly. This would increase the number publications per annum.

v. Efforts should be made by researchers to curb the problem of impact factor mania and re-adopt core scientific values. Thus, emphasis should be re-drifted from IF to scientific values such as rigorous peer review, quality research, knowledge creation and modification, societal advancement, reproducibility and problem-solving.
Author contributions: All authors were involved in concept, design, literature review, analysis, writing, and critically revising the article. All authors approved the final version of this article before submission.

Funding: The authors received no financial support for the research and/or authorship of this article.

Declaration of in terest: Authors declare no competing interest.

Data availability: No data is associated with this research, however, the authors have cited all ideas, findings and works of other scholars where applicable.

\section{REFERENCES}

Abambres, M., Ribeiro, T., Sousa, A., \& Lantsoght, E. (2016). Research counts, not the journal. HAL, 1-12. https://hal.archivesouvertes.fr/hal-02074859v3

Abramo, G., \& D'Angelo, C. A. (2016). Refrain from adopting the combination of citation and journal metrics to grade publications, as used in the Italian national research assessment exercise (VQR 2011-2014). Scientometrics, 109(3), 2053-2065. https://doi.org/ 10.1007/s11192-016-2153-5

Agarwal, A., Durairajanayagam, D., Tatagari, S., Esteves, S. C., Harlev, A., Henkel, R., Roychoudhury, S., Homa, S., Puchalt, N. G., Ramasamy, R., Majzoub, A., Dao Ly, K., Tvrda, E., Assidi, M., Kesari, K., Sharma, R., Banihani, S., Ko, E., Abu-Elmagd, M., ... Bashiri, A. (2016). Bibliometrics: Tracking research impact by selecting the appropriate metrics. Asian Journal of Andrology, 18(2), 296-309. https://doi.org/10.4103/1008-682X.171582

Aksnes, D. W., Langfeldt, L., \& Wouters, P. (2019). Citations, citation indicators, and research quality: An overview of basic concepts and theories. SAGE Open, 9(1), 215824401982957. https://doi.org/10.1177/2158244019829575

Alberts, B. (2013). Impact factor distortions. Science, 340(6134), 787. https://doi.org/10.1126/science.1240319

Aragon, A. M. (2013). A measure for the impact of research. Scientific Reports, 3, 1649. https://doi.org/10.1038/srep01649

Bassey, B. A., \& Owan, V. J. (2019). Ethical Issues in Educational Research. In P. N. Ololube \& G. U. Nwiyi (Eds.), Encyclopedia of institutional leadership, policy, and management: $A$ handbook of research in honour of Professor Ozo-Mekuri Ndimele (Vol 2, pp. 1287-1301). Pearl Publishers International Ltd. https://doi.org/10.13140/ RG.2.2.11785.88161

Baum, J. A. C. (2011). Free-riding on power laws: Questioning the validity of the impact factor as a measure of research quality in organization studies. Organization, 18(4), 449-466. https://doi.org/10.1177/1350508411403531

Biagioli, M. (2018). Quality to impact, text to metadata: Publication and evaluation in the age of metrics. KNOW A Journal on the Formation of Knowledge, 2(2), 1-27. https://doi.org/10.1086/699152

Blyth, E., Shardlow, S. M., Masson, H., Lyons, K., Shaw, I., \& White, S. (2010). Measuring the quality of peer-reviewed publications in social work: Impact factors-liberation or liability? Social Work Education, 29(2), 120-136. https://doi.org/10.1080/0261547090 2856705

Bohannon, J. (2013). Who's afraid of peer review? Science, 342, 60-65. https://doi.org/10.1126/science.342.6154.60 
Buela-Casal, G., \& Zych, I. (2012). What do scientists think about the impact factor? Scientometrics, 92(2), 281-292. https://doi.org/ 10.1007/s11192-012-0676-y

Burrows, R. (2012). Living with the h-index? Metric assemblages in the contemporary academy. Sociological Review, 60(2), 355-372.

Butler, L., \& McAllister, I. (2009). Metrics or peer review? Evaluating the 2001 UK research assessment exercise in political science. Political Studies Review, 7(1), 3-17. https://doi.org/10.1111/j.14789299.2008.00167.x

Campbell, P. (2008). Escape from the impact factor. Ethics in Science and Environmental Politics 8, 5-7. https://doi.org/10.3354/esep00078

Casadevall, A., \& Fang, F. C. (2014). Causes for the persistence of impact factor mania. MBio, 5(2), e00064-14. https://doi.org/10.1128/ mBio.00064-14

Chapman, C. A., Bicca-Marques, J. C., Calvignac-Spencer, S., Fan, P., Fashing, P. J., Gogarten, J., Guo, S., Hemingway, C. A., Leendertz, F., Li, B., Matsuda, I., Hou, R., Serio-Silva, J. C., \& Stenseth, N. C. (2019). Games academics play and their consequences: How authorship, h-index and journal impact factors are shaping the future of academia. Proceedings of the Royal Society B: Biological Sciences, 286, 2019.2047. https://doi.org/10.1098/rspb.2019.2047

Cheek, J., Garnham, B., \& Quan, J. (2006). What's in a number? Issues in providing evidence of impact and quality of research(ers). Qualitative Health Research, 16(3), 423-435. https://doi.org/10.1177/ 1049732305285701

Craig, I. D., A. M. Plume, M. E. McVeigh, J. Pringle, and M. Amin (2007). Do open-access articles have a greater citation impact? A critical review of the literature. Journal of Informetrics, 1(3), 239248. https://doi.org/10.1016/j.joi.2007.04.001

Elliott, D. B. (2014). The impact factor: A useful indicator of journal quality or fatally flawed? Ophthalmic and Physiological Optics, 34(1), 4-7. https://doi.org/10.1111/opo.12107

Eston, R., (2005). The impact factor: A misleading and flawed measure of research quality. Journal of Sports Sciences, 23(1), 1-3. https://doi.org/10.1080/02640410400014208

Fallon, L. M., Sanetti, L. M. H., \& Johnson, A. H. (2015). Is performance feedback for educators an evidence-based practice? A systematic review and evaluation based on single-case. Exceptional Children, 81(2), 227-246. https://doi.org/10.1177/0014402914551738

Folly, G., Hajtman, B., Nagy, J. I., \& Ruff, I. (1981). Some methodological problems in ranking scientists by citation analysis. Scientometrics, 3, 135-147. https://doi.org/10.1007/BF02025636

Fu, L. D., Aphinyanaphongs, Y. Y., Wang, L., \& Aliferis, C. F. (2011). A comparison of evaluation metrics for biomedical journals, articles, and websites in terms of sensitivity to topic. Journal of Biomedical Informatics, 44(4), 587-594. https://doi.org/10.1016/ j.jbi.2011.03.006

Garfield, E. (1955). Citation indexes for science: A new dimension in documentation through association of ideas. Science, 122(3159), 108-111. https://doi.org/10.1126/science.122.3159.108

Garfield, E. (1972). Citation analysis as a tool in journal evaluation. Science, 178(4060), 471-479. https://doi.org/10.1126/science.178. 4060.471
Garfield, E. (1999). Journal impact factor: A brief review. Canadian Medical Association Journal 161(8), 979-980. https://bit.ly/2WPwNvf

Garfield, E. (2006). The history and meaning of the journal impact factor. Journal of the American Medical Association, 295(1), 90-93. https://doi.org/10.1001/jama.295.1.90

Grech, V. (2018). Increasing importance of research metrics: Journal impact factor and h-index. International Urogynecology Journal, 29(5), 619-620. https://doi.org/10.1007/s00192-018-3604-8

Gruber, T. (2015). Academic sell-out: How an obsession with metrics and rankings is damaging academia. Journal of Marketing for Higher Education, 24(2), 165-177. https://doi.org/10.1080/08841241.2014. 970248

Gruber, T., Reppel, A., \& Voss, R. (2010). Understanding the characteristics of effective professors: The student's perspective. Journal of Marketing for Higher Education, 20(2), 175-190. https://doi.org/10.1080/08841241.2010.526356

Haddawy, P., Hassan, S. U., Asghar, A., \& Amin, S. (2016). A comprehensive examination of the relation of three citation-based journal metrics to expert judgment of journal quality. Journal of Informetrics, 10(1), 162-173. https://doi.org/10.1016/j.joi.2015.12. 005

Hallberg, L. (2012). Can the impact factor measure the quality of research? International Journal of Qualitative Studies on Health and Well-Being, 7(1), 2-4. https://doi.org/10.3402/qhw.v7i0.19772

Hammarfelt, B., \& Rushforth, A. D. (2017). Indicators as judgment devices: An empirical study of citizen bibliometrics in research evaluation. Research Evaluation, 26(3), 169-180. https://doi.org/ 10.1093/reseval/rvx018

Hernan, M. A. (2008). Epidemiologists (of all people) should question journal impact factors. Epidemiology, 19(3), 366-368. https://doi.org/10.1097/EDE.0b013e31816a9e28

Huggett, S. (2013). Journal bibliometrics indicators and citation ethics: A discussion of current issues. Atherosclerosis, 230(2), 275-277. https://doi.org/10.1016/j.atherosclerosis.2013.07.051

Ioannidis, J. P., Tatsioni, A., \& Karassa, F. B. (2010). Who is afraid of reviewers' comments? Or, why anything can be published and anything can be cited. Eur J Clin Invest, 40(4), 285-287. https://doi.org/10.1111/j.1365-2362.2010.02272.x

Jarwal, S. D., Brion, A. M., \& King, M. L. (2009). Measuring research quality using the journal impact factor, citations and 'Ranked Journals': Blunt instruments or inspired metrics? Journal of Higher Education Policy and Management, 31(4), 289-300. https://doi.org/10.1080/13600800903191930

Joshi, M. A. (2015). Bibliometric indicators for evaluating the quality of scientific publications. Journal of Contemporary Dental Practice, 15(2), 258-262. https://doi.org/10.5005/jp-journals-10024-1525

Kieling, C., \& Gonçalves, R. R. F. (2007). Assessing the quality of a scientific journal: The case of Revista Brasileira de Psiquiatria. Revista Brasileira de Psiquiatria, 29(2), 177-181. https://doi.org/10.1590/S1516-44462007000200017

Kiesslich, T., Weineck, S. B., \& Koelblinger, D. (2016). Reasons for journal impact factor changes: Influence of changing source items. PLoS ONE, 11(4), e0154199. https://doi.org/10.1371/journal.pone. 0154199 
Kochen, M., \& Himmel, W. (1998). A critical assessment of the impact factor. European Journal of General Practice, 4(4), 159-163. https://doi.org/10.3109/13814789809160812

Koya, K., \& Chowdhury, G. (2017). Metric-based vs peer-reviewed evaluation of research output: Lesson learnt from UK's national research assessment exercise. PLoS ONE, 12(7), 1-18 https://doi.org/10.1371/journal.pone.0179722

Kressel, H. Y. (2014). Beyond the impact factor: Enhancing the impact of imaging research published in radiology. Radiology, 270(1), 3-6. https://doi.org/10.1148/radiol.13132314

Langfeldt, L. (2001). The decision-making constraints and processes of grant peer review and their effects on the review outcome. Social Studies of Science, 31(6), 820-841. https://doi.org/10.1177/ 030631201031006002

Larsen, P. O., \& von Ins, M. (2010). The rate of growth in scientific publication and the decline in coverage provided by Science Citation index. Scientometrics, 84(3), 575-603. https://doi.org/10.1007/s11192-010-0202-z

Lawrence, P. A. (2007). The mismeasurement of science. Current Biology, 17(15), R583-R585. https://doi.org/10.1016/j.cub.2007.06. 014

Leydesdorff, L., Bornmann, L., Comins, J. A., \& Milojević, S. (2016). Citations: Indicators of quality? The impact fallacy. Frontiers in Research Metrics and Analytics, 1, 1-15. https://doi.org/10.3389/ frma.2016.00001

Lippi, G., \& Mattiuzzi, C. (2017). Scientist impact factor (SIF): A new metric for improving scientists' evaluation? Annals of Translational Medicine, 5(15), 2-5. https://doi.org/10.21037/atm.2017.06.24

Mahian, O., \& Wongwises, S. (2015). Is it ethical for journals to request self-citation? Science and Engineering Ethics, 21(2), 531-533. https://doi.org/10.1007/s11948-014-9540-1

Margolis, J. (1967). Citation indexing and evaluation of scientific papers. $\quad$ Science, $\quad 155(3767), \quad 1213-1219$ https://doi.org/10.1126/science.155.3767.1213

Mårtensson, P., Fors, U., Wallin, S. B., Zander, U., \& Nilsson, G. H. (2016). Evaluating research: A multidisciplinary approach to assessing research practice and quality. Research Policy, 45(3), 593603. https://doi.org/10.1016/j.respol.2015.11.009

Martin, B. R., \& Irvine, J. (1983). Assessing basic research: Some partial indicators of scientific progress in radio astronomy. Research Policy, 12(2), 61-90. https://doi.org/10.1016/0048-7333(83)90005-7

McKiernan, E. C., Schimanski, L. A., Nieves, C. M., Matthias, L., Niles, M. T., \& Alperin, J. P. (2019). Use of the journal impact factor in academic review, promotion, and tenure evaluations. ELife, 8, e47338. https://doi.org/10.7554/eLife. 47338

Mingers, J., \& Yang, L. (2017). Evaluating journal quality: A review of journal citation indicators and ranking in business and management. European Journal of Operational Research, 257(1), 323337. https://doi.org/10.1016/j.ejor.2016.07.058

Misteli, T. (2013). Eliminating the impact of the impact factor. Journal of Cell Biology, 201(5), 651-652. https://doi.org/10.1083/ jcb.201304162

Nature (2003). Coping with peer rejection. Nature, 425(645), 6959. https://doi.org/10.1038/425645a
Neuberger, J., \& Counsell, C. (2002). Impact factors: Uses and abuses. European Journal of Gastroenterology \& Hepatology, 14(3), 209-211. https://doi.org/10.1097/00042737-200203000-00001

Odigwe, F. N., Bassey, B. A., \& Owan, V. J. (2020). Data management practices and educational research effectiveness of university lecturers in South-South Nigeria. Journal of Educational and Social Research (JESR), 10(3), 24-34. https://doi.org/10.36941/jesr-20200042

Orduña-Malea, E., Martín-Martín, A., \& Delgado-López-Cózar, E. (2016). The next bibliometrics: ALMetrics (Author Level Metrics) and the multiple faces of author impact. Profesional de La Informacion, 25(3), 485-496. https://doi.org/10.3145/epi.2016.may. 18

Owan, V. J., \& Bassey, B. A. (2019). Data management practices in Educational Research. In N. P. Ololube \& G. U. Nwiyi (Eds.), Encyclopedia of institutional leadership, policy, and management: A handbook of research in honour of Professor Ozo-Mekuri Ndimele (Vol 2, pp. 1251-1265). Pearl Publishers International Ltd. https://doi.org/10.13140/RG.2.2.16819.04647

Parker, M., \& Jary, D. (1995). The McUniversity: Organization, management and academic subjectivity. Organization, 2(2), 319-338. https://doi.org/10.1177/135050849522013

Quan, W., Chen, B., \& Shu, F. (2017). Publish or impoverish: An investigation of the monetary reward system of science in China (1999-2016). Aslib Journal of Information Management, 69(5), 486502. https://doi.org/10.1108/AJIM-01-2017-0014

Rousseau, R. (2002). Journal evaluation: Technical and practical issues. Library Trends, 50(3), 418-439. https://bit.ly/2ySdoSm

Rowlands, I., \& Nicholas, D. (2007). The missing link: Journal usage metrics. Aslib Proceedings: New Information Perspectives, 59(3), 222228. https://doi.org/10.1108/00012530710752025

Rushforth, A., \& de Rijcke, S. (2015). Accounting for impact? The journal impact factor and the making of biomedical research in the Netherlands. Minerva, 53(2), 117-139. https://doi.org/10.1007/ s11024-015-9274-5

Saha, S., Saint, S., \& Christakis, D. A. (2003). Impact factor: A valid measure of journal quality? Journal of the Medical Library Association, 91(1), 42-46. https://bit.ly/35WGjkr

Sauder, M., \& Espeland W. N. (2009). The discipline of rankings: Tight coupling and organizational change. American Sociological Review, 74(1), 63-82. https://doi.org/10.1177/000312240907400104

Seglen, P. O. (1992). The skewness of science. Journal of the American Society for Information Science, 43(9), 628-638. https://doi.org/ 10.1002/(SICI)1097-4571(199210)43:9\%3C628::AIDASI5\%3E3.0.CO;2-0

Seglen, P. O. (1997a). Citations and journal impact factors: Questionable indicators of research quality. Allergy: European Journal of Allergy and Clinical Immunology, 52(11), 1050-1056. https://doi.org/10.1111/j.1398-9995.1997.tb00175.x

Seglen, P. O. (1997b). Why the impact factor of journals should not be used for evaluating research. British Medical Journal, 314(7079), 498502. https://doi.org/10.1136/bmj.314.7079.497 
Seglen, P. O. (1998). Citation rates and journal impact factors are not suitable for the evaluation of research. Acta Orthopaedica Scandinavica, 69(3), 224-229. https://doi.org/10.3109/1745367980 9000920

Sevinc, A. (2004). Manipulating impact factor: An unethical issue or an editor's choice? Swiss Medical Weekly, 134(27-28), 410. https://doi.org/10.4414/smw.2004.10761

Shore, C. (2010). Beyond the multiversity: Neoliberalism and the rise of the schizophrenic university. Social Anthropology, 18(1), 15-29. https://doi.org/10.1111/j.1469-8676.2009.00094.x

Smith, R. (1988). Problems with peer review and alternatives. Research Policy, 296, 774-777. https://doi.org/10.1136/bmj.296.6624.774

Smith, R. (1997). Journal accused of manipulating impact factor. BMJ, 314(7079), 461. https://doi.org/10.1136/bmj.314.7079.461d

Solimini, A. G., \& Solimini, R. (2011). Impact factor and other metrics for evaluating science: Essentials for public health practitioners. Italian Journal of Public Health, 8(1), 96-103. https://doi.org/10.2427/5650
Sugimoto, C. R., Work, S., Larivière, V., \& Haustein, S. (2017). Scholarly use of social media and altmetrics: A review of the literature. Journal of the Association for Information Science and Technology, 68(9), 2037-2062. https://doi.org/10.1002/asi.23833

Wall, H. J. (2009). Don't get skewed over by journal rankings. The B.E. Journal of Economic Analysis and Policy, 9(1), Article 34. https://doi.org/10.2202/1935-1682.2280

Weale, A. R., Bailey, M., \& Lear, P. A. (2004). The level of non-citation of articles within a journal as a measure of quality: A comparison to the impact factor. BMC Medical Research Methodology, 4(1), 14. https://doi.org/10.1186/1471-2288-4-14

Whitehouse, G. H. (2001). Citation rates and impact factors: Should they matter? British Journal of Radiology, 74(877), 1-3. https://doi.org.10.1259/bjr.74.877.740001

Willmott, H. (2011). Journal list fetishism and the perversion of scholarship: Reactivity and the ABS list. Organization, 18(4), 429442. https://doi.org/10.1177/1350508411403532 